\title{
Contar, é preciso
}

\section{Vozes femininas do Império e da República.}

LÔBO, Yolanda; FARIA, Lia (orgs.).

Rio de Janeiro: Quartet : FAPERJ, 2008.

É fato que a história das mulheres e sua inserção no espaço público foram marcadas por uma longa trajetória de preconceitos e de dificuldades, por isso faz-se, ainda hoje, necessário contar essa história tantas vezes silenciada ao longo dos séculos. E com certeza foi essa a intenção de Yolanda Lôbo e Lia Faria quando reuniram, em Vozes femininas do Império e da República, uma coletânea de artigos com a intenção de "descortinar ideologias e utopias presentes no imaginário feminino, apontando assim para a construção histórica do gênero feminino em Portugal e no Brasil" (p. 16).

Com 368 páginas, o livro publicado pela Editora Quartet e pela Fundação de Amparo à Pesquisa do Estado do Rio de Janeiro (FAPERJ), em 2008, está a serviço de contar a história das mulheres por meio de experiências pessoais que ultrapassam a esfera do individual. Pode-se afirmar que a diversidade de assuntos abordados e os diferentes enfoques são perpassados e conduzidos por dois eixos centrais: educação e gênero.

Estruturalmente, o livro apresenta-se dividido em três partes: "Falas Imperiais", "Falas Literárias" e "Falas Apaixonadas". Na primeira constam dois artigos cuja temática é a educação no Oitocentos. Na segunda aparecem cinco textos que tratam de nomes importantes de mulheres na imprensa, na educação e na literatura. E em "Falas Apaixonadas" concentram-se quatro artigos que enfocam a atuação política e as intervenções de mulheres na educação e na cultura.

Sobre educação, é possível uma "volta" ao passado com Maria Celi Chaves Vasconcelos em "Vozes femininas do Oitocentos: o papel das preceptoras nas casas brasileiras", em que a autora recupera parte da história das mulheres que encontraram nessa prática educativa um meio de subsistência. Como destaca a autora, as preceptoras foram, no século XIX, as primeiras educadoras "oficialmente instituídas que tornaram o seu 'fazer' uma 'atividade profissional' remunerada, representando a abertura do mercado de trabalho intelectual à condição feminina" (p. 38).

Sobre a educação feminina, cabe destacar o enfoque dado por Suely Gomes Costa em "Diário de uma e outras meninas: práticas domésticas e educação", em que o olhar da pesquisadora se volta ao Diário de Helena Morley, publicado em 1942. A partir das experiências pessoais vividas na infância em Diamantina, narradas no diário, registra-se "um painel de trabalho de muitas mulheres a sua volta, das mais às menos instruídas, entrelaçadas em rede, nessa luta comum por sobrevivência" (p. 67). As confissões relatam a participação de meninas nos afazeres domésticos diários e a dificuldade de conciliar a casa e a escola. Destacam, ainda, como aponta Suely, a participação feminina na captação de moedas por meio do trabalho restrito ao âmbito do lar, as chamadas "prendas femininas". Por fim, o artigo ressalta que a luta pela sobrevivência, nesses casos, criou "reiteradas restrições de acessos à educação" (p. 70).

Será a educação, ainda, pano de fundo em "Vozes católicas: um estudo sobre a presença feminina no periódico A Ordem (anos 193040)". No artigo, Ana Maria Bandeira de Mello Magaldi resgata a participação de algumas mulheres na revista e destaca o caráter de "apostolado doutrinário e espiritual" da publicação. Atenta para a participação, dentre outras, de Lúcia Miguel Pereira na seção "Crônica feminina", criada em 1932. Nas crônicas assinadas pela autora, há uma reflexão sobre os novos rumos da vida social que impactariam na condição feminina. Sobre o assunto, a cronista deixa explícita sua preocupação com risco de a mulher deixar-se seduzir por um ritmo, uma "trepidação", própria dos tempos modernos, que a conduziria ao trabalho remunerado na esfera pública, quase sempre marcado pelo individualismo. É o foco no social a maior defesa da autora, que enfatiza a importância da educação feminina para um projeto segundo o qual a mulher deveria "pôr a serviço do bem comum as riquezas de sua psicologia materna "(p. 98), como bem destaca a autora do artigo.

É ainda pelo viés da educação e da literatura que Constância Lima Duarte nos 
apresenta Nísia Floresta, nome importante no avanço da educação feminina no Brasil, que traz em quase todos os seus livros "o propósito de formar e modificar consciências" e o projeto de "alterar o quadro ideológico-social" (p. 106). Em "Nísia Floresta e a educação feminina no séc. XIX", a pesquisadora destaca o caráter inovador das ideias e práticas educativas de Nísia, como sua defesa por uma educação feminina pautada menos na educação da agulha e mais em uma formação multifacetada. Lembra ainda que, na produção da escritora, há textos que se inscrevem na tradição de uma "prosa moralista de intenção nitidamente doutrinária", com o objetivo principal de "transformar a mulher indiferente em mãe amorosa e responsável", contribuindo - sem o saber - para a cristalização de uma "mística feminina" (p. 140). A pesquisadora afirma que, a posteriori, "é fácil de perceber a manipulação ideológica desse discurso e as conseqüências na vida das mulheres" e destaca como o elogio da maternidade tornou-se uma "nova forma de enclausuramento" (p. 140).

Em "Carmen Dolores: as contradições de uma literata da virada do século", Rachel Soihet e Flávia Copio Esteves se unem para apresentar ao leitor outra mulher à frente de seu tempo. Ciente das aptidões e dos papéis de cada gênero como construções sociais, Carmen Dolores usou a escrita para tratar de assuntos de interesse das mulheres, como a desmistificação da maternidade como seu único destino e a defesa do divórcio em nome da integridade familiar, da política, da educação e do trabalho feminino. Convivem nas crônicas assinadas pela autora a busca da libertação feminina pela educação e pelo trabalho e a manutenção de alguns comportamentos femininos. Tal paradoxo, claramente apontado pelas autoras, deve-se ao fato de que a escritora é, como tantas outras, uma "expressão da cultura de seu tempo e de sua classe", sendo preciso considerar "a flexibilidade da 'jaula' representada pela cultura" (p. 165-166).

Pelo viés memorialístico e pelo cunho autobiográfico dos diários, dos cadernos de anotações e dos álbuns de memórias da professora Maria Luiza Schmidt Rehder, textos analisados por Marilena A. Jorge Guedes de Camargo, em "Ecos de um passado feminino: entre escritos e sentimentos", chegam a nós relatando a trajetória de uma mulher movida pelos sentimentos que se propõe a "fazer história com sua experiência". Assim, ao narrar sua vida, em Rio Claro, registra também acontecimentos importantes da década de 1930. Relata, por exemplo, a formação de um exército de voluntários unidos sob ideais patrióticos em defesa de São Paulo e registra a participação das muIheres paulistas na Revolução de 1932, costurando fardas e cobertores, angariando donativos para a manutenção dos batalhões, além da atuação das enfermeiras em hospitais de campanha.

Ao falar da condição feminina impressa no romance $A$ doce canção de Caetana, de Nélida Piñon, Tânia Navarro Swain propõe uma "leitura ativa" que em nada se pretende imparcial ou distanciada, "apropriando-se" da narrativa para criar e atribuir-lhe sentidos múltiplos. Assim, em "A doce canção de Caetana: meu olhar" busca investigar as imagens e representações sociais do feminino e do masculino que habitam o romance. Discute, entre outros assuntos, a instituição do casamento como valor social na manutenção do poder masculino; a "ilusória força masculina" pautada no "fantasma da potência sexual" e na "posse de corpos alheios"; e a prostituição como "criação social", na qual, como destaca a autora, há "violência de corpos desprovidos de subjetividade" (p. 216).

Atravessando o Atlântico, Áurea Adão e Maria José Remédios detêm-se na participação política das mulheres em Portugal de 1946 a 1961. Em "Os discursos do poder e as políticas educativas na governação de Oliveira Salazar: as intervenções das mulheres na Assembléia Nacional", as autoras atentam para a atuação das deputadas na Assembleia Nacional bem como para a imagem do feminino que subjaz, explícita ou implicitamente, nas suas intervenções. Para tanto, analisam os discursos de seis mulheres parlamentares e observam que algumas áreas estavam restritas à intervenção pública feminina: a educação, a família, a assistência social e a saúde. Toda tentativa de ir além de tais assuntos era marcada por justificativas das parlamentares diante de seus pares. Ainda nos discursos dessas mulheres pode-se perceber, como destacam as autoras, a defesa da permanência da mulher no âmbito do lar, numa "valorização da função de mãe de família" e de "guardiã vigilante da harmonia e da felicidade do lar", numa "verdadeira vocação de mulher" (p. 272), contribuindo para a manutenção de um questionável modelo social.

Seguindo ainda a trilha de mulheres que fizeram história, Lia Ciomar Macedo de Faria, Edna Maria dos Santos e Rosemaria J. Vieira da Silva seguem os passos da professora e historiadora Maria Yeda Linhares. De perfil "questionador 
e combativo" e de trajetória marcada "pela irreverência e coragem intelectual", Maria Yeda se colocou em defesa do direito à educação e à garantia de uma escola pública efetivamente republicana, pois, para ela, segundo destacam as autoras em "Os múltiplos olhares de Maria Yeda Linhares: educação, história e política no feminino", o sucesso da escola pública significa uma "questão de sobrevivência se quisermos existir como povo e nação" (p. 297).

A trajetória de outra professora, Myrthes de Luca Wenzel, também é abordada em "Alcachofras-dos-telhados: lições de pedagogia de uma educadora", por Yolanda Lôbo. À frente da Secretaria Estadual de Educação e Cultura do Rio de Janeiro, a educadora reuniu em torno de si um seleto grupo de intelectuais e foi, como destaca a autora do artigo, idealizadora de uma "pedagogia libertadora", uma proposta educacional inovadora, que buscava a felicidade dos alunos, "com liberdade de criar, de viver em sociedade e ao mesmo tempo preparados de modo completo e científico" (p. 316).

Voltando-se ao espaço sociocultural português, Zília Osório de Castro, em "Na senda do feminismo intelectual", discute a condição feminina a partir da reflexão do papel do intelectual. Destaca a criação das revistas Pensamento, O Diabo e O Sol Nascente, na década de 1930, que "apostavam na reforma cultural" e traziam em suas páginas o tema do feminismo em meio ao "confronto de valores culturais presente na sociedade portuguesa de então" (p. 340). A participação das mulheres nessas revistas representou, segundo a autora, uma evolução, seja por sua inserção em um espaço majoritariamente masculino, seja pelo reconhecimento de suas potencialidades e sua "comparticipação na criação da nova sociedade" ou pela "conscientização de uma outra idéia de mulher" (p. 340), ser humano dotado de direitos e deveres. Por meio dessas mulheres se deu um "feminismo interventivo e não apenas participativo, um feminismo cívico e não apenas político" (p. 341). Zília lembra o nome de Ana de Castro Osório no feminismo cultural dos anos 1930, que defendia o trabalho como "carta de alforria" da mulher com o objetivo de responsabilizá-la por seu próprio destino. Observa ainda, nos periódicos analisados, dois tipos de feminismo: um "feminismo feminino", pelo qual a mulher reivindicava uma função social, além da revisão da sua situação familiar, profissional e política; e um "feminismo masculino", pelo qual os homens escreviam em "defesa" das mulheres.

É interessante notar, pela leitura dos artigos reunidos em Vozes femininas do Império e da República, como o lento processo de "libertação" da mulher está ligado à promoção de sua educação, de seu desenvolvimento intelectual e de seu trabalho, reafirmando o que Virgínia Woolf teorizou tão bem em Um teto todo seu. O leitor que se aventurar nas instigantes trilhas propostas pelas autoras deste livro chegará ao final de sua leitura com a visão panorâmica das principais lutas e obstáculos vivenciados pelas mulheres ao longo dos séculos, em diferentes contextos, dos quais o reconhecimento da diferença e o direito à educação foram fundamentais ao que se convencionou chamar de feminismo.

Pode-se dizer que, nas páginas deste livro, configura-se um feminismo crítico através das vozes de 13 mulheres que se unem para contar histórias de outras mulheres, que, por sua vez, superam os relatos pessoais e fazem coro com as autoras dos artigos para narrarem juntas uma história bem mais ampla: a história das mulheres.

Kelen Benfenatti Paiva Universidade Federal de Minas Gerais 